\title{
Impact of insulin resistance and metabolic syndrome on disability in patients with multiple sclerosis
}

\author{
Rasha Hassan Soliman', Hanan Mohamed Farhan², Mohamed Hegazy ${ }^{3}$, Mohammed Ibrahim Oraby', \\ Shaimaa Hossam Kamel ${ }^{1}$ and Amr Hassan ${ }^{3^{*}}$ (D)
}

\begin{abstract}
Background: Currently, little is known regarding the association of metabolic comorbidities and disability among multiple sclerosis (MS) patients.

Objectives: To evaluate insulin resistance (IR) and metabolic syndrome (MetS) in multiple sclerosis patients and their effect on disease progression and disability.

Subjects and methods: This case-control study was conducted on 50 MS patients and 25 healthy individuals. They were subjected to clinical evaluation and laboratory assessment for metabolic syndrome and insulin resistance. The homeostasis model assessment (HOMA) was used as a measurement of insulin sensitivity. Disability was evaluated by the Extended Disability Status Scale (EDSS).
\end{abstract}

Results: As compared to control group, MS patients had a significantly higher prevalence of metabolic syndrome ( $22 \%$ vs $8 \%, p=0.04)$ and insulin resistance ( $46 \%$ vs $0 \%, p<0.001)$. Patients group had significantly higher systolic blood pressure $(p=0.005)$, waist circumference $(p<0.001)$, fasting blood sugar $(p<0.001)$, insulin level $(p=0.001)$, low-density lipoproteins $(p=0.01)$, triglycerides $(p=0.02)$, HOMA-IR $(p<0.001)$, and significantly lower high-density lipoproteins $(p=0.01)$. No differences in neurological disability was reported between patients who have MetS $(p=$ $0.7)$ or IR ( $p=0.3)$ and those who do not.

Conclusion: Insulin resistance and metabolic syndrome are more prevalent among MS patients; however, their association with disability and disease progression is questionable.

Keywords: Insulin resistance, Metabolic syndrome, Multiple sclerosis, Disability, EDSS

\section{Introduction}

Multiple sclerosis (MS) is the most common nontraumatic cause of neurological disability in young adults in developed countries [1]. Metabolic syndrome (MetS), by definition, is not a disease, but is a clustering of individual risk factors for disease, giving the attention of the clinician to the probable coexistence of multiple cardiometabolic risk factors in patients when one of the components is found [2]. Metabolic syndrome is a multiplex risk factor that arises from insulin resistance (IR) accompanying abnormal adipose deposition

\footnotetext{
* Correspondence: amrhasanneuro@kasralainy.edu.eg

${ }^{3}$ Neurology Department, Kasr Al Ainy Hospital, Faculty of Medicine, Cairo

University, Cairo, Egypt

Full list of author information is available at the end of the article
}

and function [3]. From the existing studies, it is still unclear whether the increased risk of cardiovascular disease is related to an increased risk of hypertension, dyslipidemia, obesity, changes in body composition, or type II diabetes in MS patients, indicating the need for advanced research in this field if we are to advise MS patients adequately in avoiding preventable or potentially modifiable comorbidities [4]. Adiposity and IR are important pathophysiological mechanisms underlying atherosclerosis, but until now, little is known about their association with disease progression and disability in patients with MS. Additionally, IR prevalence in individuals with MS has not been determined yet [5]. The aim of this work is to evaluate insulin resistance and metabolic syndrome in multiple sclerosis patients and 
their potential effects on disease progression and disability. Preliminary results have been presented as a poster in ECTRIMS Paris 2017 and were published in the conference proceedings [6].

\section{Subjects and methods}

This case-control study was conducted on fifty patients with multiple sclerosis from all types (relapsing-remitting, primary progressive, and secondary progressive) fulfilling the revised McDonald's Criteria for diagnosis of multiple sclerosis 2010 [7]. They were recruited from Neurology Department, Beni-Suef University Hospital and Kasr AlAiny Multiple Sclerosis Unit (KAMSU), Cairo University. Patients group included 34 females $(68 \%)$ and 16 males (32\%) whose age ranged from 24 to 48 years. Twenty-five healthy volunteers matched for age and sex were included as a control group. We had excluded patients with diabetes mellitus, hypertension, cardiac disease, alcoholic patients and those who were on a specific diet. We had also excluded patients using any anti-inflammatory drugs, cholesterol-lowering agents, estrogen replacement therapy, steroid therapy or other drugs that could affect the metabolic profile. The study was approved by the institutional review board of Beni-Suef University. An informed consent has been obtained from all patients upon enrollment in the study.

\section{Clinical evaluation}

Blood pressure measurement: systolic blood pressure (SBP) and diastolic blood pressure (DBP) were measured. The mean of two BP measurements, taken with a 1-min interval between them after participants had been seated, was used for the statistical analysis [8]. Waist circumference (WC) was measured with a soft tape on standing patients midway between the lowest rib and the iliac crest [9]. Expanded disability status scale was used as a measure of disability in MS group [10].

\section{Laboratory work}

Peripheral blood samples from patients and control groups were collected with $\mathrm{Na}$ fluoride as an anticoagulant for blood glucose and without anticoagulant for the rest of the tests after fasting. All of the samples were immediately centrifuged at $3000 \mathrm{~g}$ for $15 \mathrm{~min}$ and separated into aliquots. Routine tests were done immediately but the rest of sera were stored in the freezer $(-80 \mathrm{C})$ until use for measuring fasting insulin. Total cholesterol, high-density lipoprotein cholesterol (HDL-C), triglycerides (TG), low-density lipoprotein cholesterol (LDL-C), fasting glucose and fasting insulin levels were evaluated. The homeostasis model assessment (HOMA) was used as a measurement of insulin sensitivity [11]. HOMA for insulin resistance (HOMA-IR) was calculated using the following equation: insulin fasting $(\mathrm{mU} / \mathrm{mL}) \times$ glucose fasting $(\mathrm{nmol} / \mathrm{L}) / 22.5$. Patients were considered to have insulin resistance when the result of HOMA-IR was > 2.5. Patients were assessed for metabolic syndrome using National Cholesterol Education Program's Adults Treatment Panel III (NCEP-ATP III Criteria) which requires combination of three or more of the following criteria to confirm the diagnosis of MetS: abdominal obesity (waist circumference): men $>102 \mathrm{~cm}$ ( $>40$ in), women $>88 \mathrm{~cm}$ (>35 in), triglycerides $\geq 150 \mathrm{mg} / \mathrm{dL}$, blood pressure $\geq$ $135 / \geq 85 \mathrm{mmHg}$, fasting glucose $\geq 100 \mathrm{mg} / \mathrm{dL}$, and HDL cholesterol: men $<40 \mathrm{mg} / \mathrm{dL}$, women $<40 \mathrm{mg} / \mathrm{dL}$ [12].

\section{Statistical analysis}

Data were statistically described in terms of mean standard deviation (SD), range, and $95 \% \mathrm{CI}$ or frequencies (number of cases) and percentages when appropriate. A comparison of numerical variables between the study groups was done using Student $t$ test for independent samples in comparing 2 groups of normally distributed data and Mann Whitney $U$ test for independent samples for comparing non-normal data. Within-group comparison of numerical variables was done using paired $t$ test. For comparing categorical data, Chi-square [2] test was performed. Exact test was used instead when the expected frequency is less than 5 . Correlation between various variables was done using Spearman rank correlation equation. $p$ values less than 0.05 were considered statistically significant. All statistical calculations were done using computer program SPSS (Statistical Package for the Social Science; SPSS Inc., Chicago, IL, USA) release 15 for Microsoft Windows (2006).

\section{Results}

\section{Demographic and clinical characteristics of the participants}

Demographic and clinical characteristics of the participants are presented in Table 1.

\section{Comparative results}

\section{MetS components and insulin resistance}

As compared to the control group, MS patients had a significantly higher prevalence of metabolic syndrome $(22 \%$ vs $8 \%, p=0.04)$ and insulin resistance $(46 \%$ vs $0 \%$, $p<0.001)$. As regards the components of MetS, $30 \%$ of the MS group had fasting glucose $\geq 100 \mathrm{mg} / \mathrm{dL}$ ( $p<$ $0.001), 30 \%$ had blood pressure $\geq 130 / 85 \mathrm{mmHg}(p<$ $0.001), 14 \%$ had triglycerides $\geq 150 \mathrm{mg} / \mathrm{dL}(p<0.001)$, $34 \%$ had HDL-C $<40 \mathrm{mg} / \mathrm{dL}$ in men or $<50 \mathrm{mg} / \mathrm{dL}$ in women $(p<0.001)$, and $38 \%$ had waist circumference $\geq$ $102 \mathrm{~cm}$ in men or $\geq 88 \mathrm{~cm}$ in women $(p<0.001)$ (Table 2). Patients group had significantly higher numerical values of systolic blood pressure $(p=0.005)$, waist circumference $(p<0.001)$, FBS $(p<0.001)$, insulin level 
Table 1 Demographic characteristics of both groups

\begin{tabular}{lll}
\hline & $\begin{array}{l}\text { Patient group } \\
(n=50)\end{array}$ & $\begin{array}{l}\text { Control group } \\
(n=25)\end{array}$ \\
\hline Age (mean \pm SD) & $34.1 \pm 6.7$ & $35.2 \pm 13.2$ \\
Sex & & $14(56 \%)$ \\
$\quad$ Males $[n(\%)]$ & $16(32 \%)$ & $11(44 \%)$ \\
$\quad$ Females $[n(\%)]$ & $34(68 \%)$ & 0.6 \\
Age of onset of the disease (years) (mean \pm SD) & $34.1 \pm 6.8$ & \\
Disease duration (years) (mean \pm SD) & $7.3 \pm 5.1$ & \\
Duration since the last attack (months) (mean \pm SD) & $16.41 \pm 18.1$ & \\
EDSS (mean \pm SD) & $2.9 \pm 1.4$ & \\
MS type & & \\
RRMS $[n(\%)]$ & $40(80 \%)$ & \\
SPMS $[n(\%)]$ & $8(16 \%)$ & $2(4 \%)$ \\
PPMS $[n(\%)]$ & & \\
\hline
\end{tabular}

EDSS Expanded Disability Status Scale, RRMS Relapsing-remitting multiple sclerosis, SPMS Secondary progressive multiple sclerosis, PPMS Primary progressive multiple sclerosis

$(p=0.001), \quad$ LDL $\quad(p=0.01)$, triglycerides $(p=0.02)$, HOMA-IR $(p<0.001)$, and significantly lower HDL $(p=$ 0.01 ) as compared to control group (Table 3).

HOMA-IR was abnormal in $46 \%$ of MS patients while $54 \%$ of the patient and $100 \%$ of the control had normal values. This difference was statistically significant $(p$ value $<0.001$ ) (Fig. 1).

No differences in neurological disability as measured by the EDSS was reported between MS patients who have MetS $(p=0.7)$ or insulin resistance $(p=0.3)$ and those who do not (Table 4). Moreover, significant differences between the 2 groups in the individual components of MetS were not associated with the significant difference in disability (Table 4).

\section{Discussion}

The results of our study revealed a significantly higher prevalence of metabolic syndrome (22\%) and insulin resistance (46\%) among MS patients as compared to healthy control. Our results are matching with PinhasHamiel and colleagues, who found that $30 \%$ of MS patients had metabolic syndrome [13]. Another study also reported higher values of insulin and HOMA-IR in MS patients [14].

If we analyze the results of the individual components of MetS, 30\% of our MS group had fasting glucose $\geq$ $100 \mathrm{mg} / \mathrm{dL}, 30 \%$ had blood pressure $\geq 130 / 85 \mathrm{mmHg}$, $14 \%$ had triglycerides $\geq 150 \mathrm{mg} / \mathrm{dL}, 34 \%$ had low HDL$\mathrm{C}$, and $38 \%$ had high waist circumference $(\geq 102 \mathrm{~cm}$ in men or $\geq 88 \mathrm{~cm}$ in women). These results are comparable to a previous study that found that $56.1 \%$ of disabled MS patients had central obesity by waist circumference, $27.7 \%$ were treated for hypertension, $17.7 \%$ had elevated blood pressure, $35.5 \%$ had fasting hyperglycemia, $26.1 \%$ had elevated TG level and $28 \%$ had low HDL-C [13].

Table 2 Prevalence of MetS and its individual components in both groups

\begin{tabular}{llll}
\hline Metabolic syndrome components & $\begin{array}{l}\text { Patient group } \\
(n=50) \\
N(\%)\end{array}$ & $\begin{array}{l}\text { Control group } \\
(n=25) \\
N(\%)\end{array}$ & 0 value \\
\hline Fasting glucose $\geq 100 \mathrm{mg} / \mathrm{dL}$ & $15(30 \%)$ & $2(8 \%)$ & $0.001^{*}$ \\
Blood pressure $\geq 130 / 85 \mathrm{mmHg}$ & $15(30 \%)$ & $0(0 \%)$ & $0.03^{*}$ \\
Triglycerides $\geq 150 \mathrm{mg} / \mathrm{dL}$ & $7(14 \%)$ & $4(16 \%)$ & 0.08 \\
$\mathrm{HDL}-\mathrm{C}<40 \mathrm{mg} / \mathrm{dL}$ in men or $<50 \mathrm{mg} / \mathrm{dL}$ in women & $17(34 \%)$ & $0(0 \%)$ & $<0.2$ \\
Waist circumference $\geq 102 \mathrm{~cm}$ in men or $\geq 88 \mathrm{~cm}$ in women & $19(38 \%)$ & $23(92 \%)$ \\
Metabolic syndrome & & $2(8 \%)$ \\
No & $39(78 \%)$ & $11(22 \%)$ & 0.04 \\
Yes & &
\end{tabular}


Table 3 MetS components and insulin resistance in both groups

\begin{tabular}{llll}
\hline & $\begin{array}{l}\text { Patient group } \\
(n=50) \\
\text { mean } \pm \text { SD }\end{array}$ & $\begin{array}{l}\text { Control group } \\
(n=25) \\
\text { mean } \pm \text { SD }\end{array}$ & $p$ value \\
\hline Systolic blood pressure & $121.2 \pm 17.5$ & $109.8 \pm 13.1$ & $0.005^{*}$ \\
Diastolic blood pressure & $74.4 \pm 14.3$ & $69.4 \pm 10.2$ & 0.1 \\
Waist circumference & $83.8 \pm 14$ & $72.2 \pm 8.5$ & $<0.001^{*}$ \\
FBS (mg/dl) & $97.6 \pm 13.4$ & $85.9 \pm 8.2$ & $<0.001^{*}$ \\
Insulin level (mU/L) & $16.7 \pm 16.7$ & $4.7 \pm 1.7$ & $0.001^{*}$ \\
HDL (mg/dL) & $49.6 \pm 6.4$ & $53.8 \pm 7.2$ & $0.01^{*}$ \\
LDL (mg/dL) & $117.3 \pm 48.5$ & $79.9 \pm 26.6$ & $0.001^{*}$ \\
Triglycerides (mg/dL) & $103.9 \pm 53.2$ & $79.4 \pm 20.9$ & $0.02^{*}$ \\
HOMA-IR & $3.9 \pm 3.9$ & $0.99 \pm 0.39$ & $<0.001^{*}$ \\
\hline
\end{tabular}

FBS Fasting blood sugar, HDL High-density lipoprotein, LDL Low-density lipoprotein, HOMA-IR The homeostasis model assessment for insulin resistance ${ }^{*} p$ value $<0.05$ is considered statistically significant

We found that metabolic syndrome components and insulin resistance were not associated with disability in MS patients. Several studies showed conflicting results as regard this association. Some studies found no difference in EDSS between MS cases with and without metabolic syndrome $[13,15]$. Others showed that insulin and HOMAIR were associated with progressive disability [14].

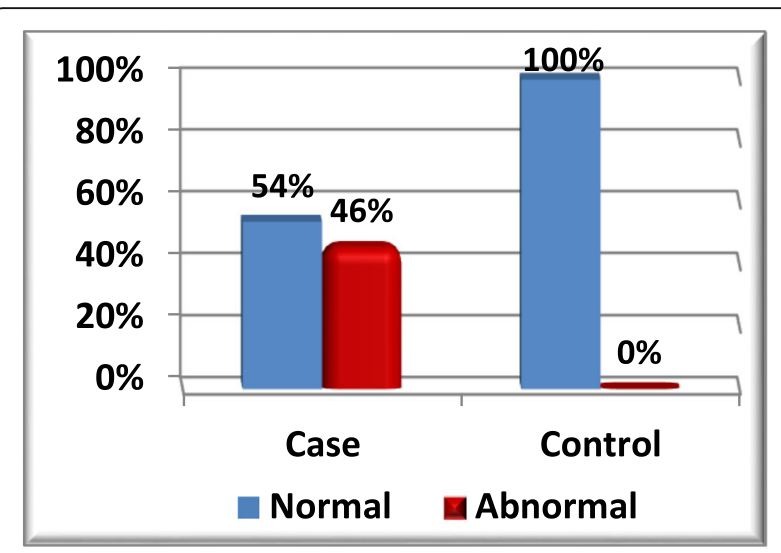

Fig. 1 Prevalence of HOMA-IR in both groups ( $p$ value $<0.001$ )

Increased prevalence of overweight and obesity among patients with MS has been reported [16-18]. A previous study showed that MS patients had increased adiposity in the form of increased WC and stated that there were statistically significant negative correlations between physical activity levels and WC, indicating that lower levels of physical activity are associated with higher levels of WC [17]. WC is better than Body Mass Index (BMI) in assessment of obesity in disabled patients as

Table 4 Relation between metabolic syndrome components, HOMA-IR and EDSS scores among MS patients

\begin{tabular}{|c|c|c|}
\hline Metabolic syndrome items & EDSS score (mean \pm SD) & $p$ value \\
\hline \multicolumn{3}{|l|}{ Fasting glucose } \\
\hline$\geq 100 \mathrm{mg} / \mathrm{dL}$ & $2.8 \pm 1.4$ & \multirow[t]{2}{*}{0.3} \\
\hline$\leq 100 \mathrm{mg} / \mathrm{dL}$ & $3.3 \pm 1.3$ & \\
\hline \multicolumn{3}{|l|}{ Blood pressure } \\
\hline$\geq 130 / 85 \mathrm{mmHg}$ & $2.9 \pm 1.3$ & \multirow[t]{2}{*}{0.6} \\
\hline$\leq 130 / 85 \mathrm{mmHg}$ & $3.1 \pm 1.4$ & \\
\hline \multicolumn{3}{|l|}{ Triglycerides } \\
\hline$\geq 150 \mathrm{mg} / \mathrm{dL}$ & $3.01 \pm 1.4$ & \multirow[t]{2}{*}{0.5} \\
\hline$\leq 150 \mathrm{mg} / \mathrm{dL}$ & $2.6 \pm 0.56$ & \\
\hline \multicolumn{3}{|l|}{$\mathrm{HDL}-\mathrm{C}$} \\
\hline$<40 \mathrm{mg} / \mathrm{dL}$ in men or $<50 \mathrm{mg} / \mathrm{dL}$ in women & $3.2 \pm 1.6$ & \multirow[t]{2}{*}{0.2} \\
\hline$>40 \mathrm{mg} / \mathrm{dL}$ in men or $>50 \mathrm{mg} / \mathrm{dL}$ in women & $2.6 \pm 0.67$ & \\
\hline \multicolumn{3}{|l|}{ Waist circumference } \\
\hline$\geq 102 \mathrm{~cm}$ in men or $\geq 88 \mathrm{~cm}$ in women & $2.9 \pm 1.5$ & \multirow[t]{2}{*}{0.8} \\
\hline$\leq 102 \mathrm{~cm}$ in men or $\leq 88 \mathrm{~cm}$ in women & $3 \pm 1.1$ & \\
\hline \multicolumn{3}{|l|}{ Metabolic syndrome } \\
\hline No & $2.9 \pm 1.5$ & \multirow[t]{2}{*}{0.7} \\
\hline Yes & $2.8 \pm 0.8$ & \\
\hline \multicolumn{3}{|l|}{ HOMA-IR } \\
\hline Normal & $3.1 \pm 1.6$ & \multirow[t]{2}{*}{0.3} \\
\hline Abnormal & $2.7 \pm 1$ & \\
\hline
\end{tabular}


BMI may be biased because of changes in the relative proportion of muscle and fat in persons with disability, whereas WC, a measure of central adiposity, may reflect more accurately the relative increase in body fat [19]. Regarding blood pressure, our results showed an increase in systolic blood pressure in patients of MS than control subjects with no statistically significant difference as regards diastolic blood pressure. These findings are supported by Buchanan and colleagues who stated that MS patients had an increased risk of hypertension [20]. In contrast to our findings, Oliveira and colleagues found that MS patients showed higher diastolic blood pressure than control subjects [14]. Sternberg and colleagues also stated that MS patients had lower systolic BP than non-MS patients [21]. In contrast to our results regarding blood pressure and disability in MS patients, Marrie and colleagues reported that hypertension was associated with an increased risk for disability [22].

Regarding the lipid profile, similar to our findings, some studies found that MS patients had higher LDLcholesterol, triglycerides and lower HDL-cholesterol than control subjects $[14,17]$ while results of other studies demonstrated insignificant differences [23, 24].

Several studies had demonstrated an association between dyslipidemia and disability in MS patients $[14,22,25]$. Differently from these studies, we did not find such association.

This study has certain limitations that should be mentioned. First, the cross-sectional design. Longitudinal research is needed to confirm the changes in MetS components and their association with further disability. Second, the data regarding the metabolic syndrome components prior to the diagnosis of MS were not available. Third, the effect of prior use of steroids during relapses on components of metabolic syndrome was not studied. Fourth, a number of factors that are known to affect body weight were not studied, such as genetics and family history of obesity, composition of meals, physical activity, and lifestyle.

\section{Conclusion}

We concluded that insulin resistance and metabolic syndrome are more prevalent among multiple sclerosis patients but their association with disability and disease progression is still doubtful.

\section{Acknowledgements}

Not applicable.

\section{Authors' contributions}

SH had collected patient data and performed neurological assessment, RHS and $\mathrm{AH}$ analyzed and interpreted the patient data, HMF performed lab testing. $\mathrm{MH}$ and $\mathrm{MO}$ had performed a major contribution in writing the manuscript. All authors read and approved the final manuscript.

\section{Funding}

The authors confirm that no funds was received for this work.

\section{Availability of data and materials}

The datasets generated during and/or analyzed during the current study are available from the corresponding author on reasonable request.

\section{Ethics approval and consent to participate}

Ethical approval was obtained from the Institutional Review Board for Human Subject Research at Beni-Suef University, Egypt, on 21st April 2016. Informed written consent to participate in the study has been obtained from participants upon enrollment.

\section{Consent for publication}

Not applicable.

\section{Competing interests}

The authors declare that they have no competing interests.

\section{Author details}

${ }^{1}$ Neurology Department, Faculty of Medicine, Beni-Suef University, Beni-Suef, Egypt. ${ }^{2}$ Department of Clinical and Chemical Pathology, Faculty of Medicine, Beni-Suef University, Beni-Suef, Egypt. ${ }^{3}$ Neurology Department, Kasr Al Ainy Hospital, Faculty of Medicine, Cairo University, Cairo, Egypt.

Received: 2 February 2019 Accepted: 20 January 2020

Published online: 30 January 2020

References

1. Noseworthy JH, Lucchinetti C, Rodriguez M, Weinshenker BG. Multiple sclerosis. N Engl J Med. 2000;343:938-52.

2. Kahn R. Metabolic syndrome: is it a syndrome? Does it matter? Circulation. 2007;115(13):1806-10

3. Olufadi R, Byrne CD. Clinical and laboratory diagnosis of the metabolic syndrome. J Clin Pathol. 2008;61(6):697-706.

4. Wens I, Dalgas U, Stenager E, Eijnde BO. Risk factors related to cardiovascular diseases and the metabolic syndrome in multiple sclerosis a systematic review. Mult Scler. 2013;19(12):1556-64.

5. Dichi I, Simão ANC. Metabolic syndrome: new targets for an old problem. Expert Opin Ther Targets. 2012;16:147-50.

6. Soliman RH, Hassan A, Farhan HM, Hegazy M, Oraby MI, Kamel SH. Impact of insulin resistance and metabolic syndrome on disability and disease progression in patients with multiple sclerosis. Mult Scler J. 2017;23:487.

7. Polman $\mathrm{CH}$, Reingold SC, Banwell B, Clanet $M$, Cohen JA, Filippi $M$, et al. Diagnostic criteria for multiple sclerosis: 2010 revisions to the McDonald criteria. Ann Neurol. 2011;69:292-302.

8. Pickering TG, Hall JE, Appel LJ, Falkner BE, Graves J, Hill MN, et al. Recommendations for blood pressure measurement in humans and experimental animals: part 1: blood pressure measurement in humans: a statement for professionals from the subcommittee of professional and public education of the American Heart Association Council on high blood pressure research. Circulation. 2005;111:697-16.

9. Lean MEJ, Han TS, Morrison CE. Waist circumference as a measure for indicating need for weight management. BMJ. 1995;311:158-61.

10. Kurtzke JF. Rating neurologic impairment in multiple sclerosis: an expanded disability status scale (EDSS). Neurology. 1983;33:1444-52.

11. Haffner SM, Miettinen H, Stern MP. The homeostasis model in the San Antonio heart study. Diabetes Care. 1997;20(7):1087-92.

12. Expert Panel on Detection E. Executive Summary of The Third Report of The National Cholesterol Education Program (NCEP) Expert Panel on Detection, Evaluation, And Treatment of High Blood Cholesterol In Adults (Adult Treatment Panel III). J Am Med Assoc. 2001;285:2486-97.

13. Pinhas-Hamiel O, Livne M, Harari G, Achiron A. Prevalence of overweight, obesity and metabolic syndrome components in multiple sclerosis patients with significant disability. Eur J Neurol. 2015;22(9):1275-9.

14. Oliveira SR, Simão ANC, Kallaur AP, de Almeida ARC, Morimoto HK, Lopes J, et al. Disability in patients with multiple sclerosis: influence of insulin resistance, adiposity, and oxidative stress. Nutrition. 2014;30:268-73.

15. Morales IB, Saipetch C, Turetsky A, Kane K, Garg N, Riskind P. Metabolic syndrome and disability in multiple sclerosis: a retrospective study. Neurology. 2014;82(10):P6.168.

16. Marck CH, Neate SL, Taylor KL, Weiland TJ, Jelinek GA. Prevalence of comorbidities, overweight and obesity in an international sample of people 
with multiple sclerosis and associations with modifiable lifestyle factors. PLOS ONE. 2016;11(2):e0148573.

17. Slawta JN, Wilcox AR, McCubbin JA, Nalle DJ, Fox SD, Anderson G. Health behaviors, body composition, and coronary heart disease risk in women with multiple sclerosis. Arch Phys Med Rehabil. 2003;84:1823-30.

18. Snook EM, Mojtahedi MC, Evans EM, McAuley E, Motl RW. Physical activity and body composition among ambulatory individuals with multiple sclerosis. Int J MS Care. 2005;7(4):137-42.

19. Alschuler KN, Gibbons LE, Rosenbergetal DE, Ehde DM, Verrall AM, Bamer $\mathrm{AM}$, et al. Body mass index and waist circumference in persons aging with muscular dystrophy, multiple sclerosis, post-polio syndrome, and spinal cord injury. Disabil Health J. 2012;5(3):177-84.

20. Buchanan RJ, Schiffer R, Stuifbergen A, Zhu L, Wang S, Chakravorty BJ, et al. Demographic and disease characteristics of people with multiple sclerosis living in urban and rural areas. Int J MS Care. 2006;8:89-97.

21. Sternberg Z, Leung C, Sternberg D, Li F, Karmon Y, Chadha K, Levy E. The prevalence of the classical and non-classical cardiovascular risk factors in multiple sclerosis patients. CNS Neurol Disord Drug Targets. 2013;12:104-11.

22. Marrie RA, Rudick R, Horwitz R, Cutter G, Tyry T, Campagnolo D. Vascular morbiditiy is associated with more rapid disability progression in multiple sclerosis. Neurology. 2010;74:1041-7.

23. Comoúlu S, Yardimci S, Okcu Z. Body fat distribution and plasma lipid profiles of patients with multiple sclerosis. Turk J Med Sci. 2004;34:43-8.

24. Navarro X, Segura R. Plasma lipids and their fatty acid composition in multiple sclerosis. Acta Neurol Scand. 1988;78(2):152-7.

25. Tettey P, Simpson S Jr, Taylor B. An adverse lipid profile is associated with disability and progression in disability, in people with MS. Mult Scler. 2014; 20:1737-44

\section{Publisher's Note}

Springer Nature remains neutral with regard to jurisdictional claims in published maps and institutional affiliations.

\section{Submit your manuscript to a SpringerOpen ${ }^{\circ}$ journal and benefit from:}

- Convenient online submission

- Rigorous peer review

- Open access: articles freely available online

High visibility within the field

- Retaining the copyright to your article

Submit your next manuscript at $\boldsymbol{\nabla}$ springeropen.com 